\title{
Decreases in Serum Triacylglycerol and Visceral Fat Mediated by Dietary Soybean $\beta$-conglycinin
}

\author{
Mitsutaka Kohno ${ }^{1}$, Motohiko Hirotsuka ${ }^{1}$, Makoto Kito ${ }^{1,3}$, and Yuji Matsuzawa² \\ ${ }^{1}$ Food Science Research Institute, Fuji Oil Co., Ltd., Osaka, Japan. \\ ${ }^{2}$ Sumitomo Hospital, Osaka, Japan. \\ ${ }^{3}$ Emeritus Professor of Kyoto University, Kyoto, Japan.
}

\begin{abstract}
Soy protein isolate (SPI) is known to reduce the risk of heart disease by lowering serum cholesterol and triacylglycerol (TG) levels. Soybean $\beta$-conglycinin, which is a component of SPI, might be the active ingredient that prevents and/or ameliorates lifestyle-related diseases, such as hyperlipidemia and obesity. This study aimed to determine the efficacy of soybean $\beta$-conglycinin for lowering the human serum TG level and visceral fat. Randomized double-blind placebo-controlled designs were used to test the effect of dietary $\beta$-conglycinin, which was taken in the form of candy. [Test 1]-In order to examine the serum TG level, 138 volunteers aged 26 to 69 years with TG concentrations above $1.69 \mathrm{mmol} / \mathrm{L}$ participated in the study. The subjects were divided at random into two different groups: the test group only consumed the experimental candy containing $\beta$-conglycinin and the placebo group only consumed the placebo candy containing casein. The test period consisted of a 2 -wk pre-evaluation phase to screen the participants, a 12 -wk consumption period and a 4-wk postevaluation phase. The serum TG concentrations were significantly reduced in the test group, compared with the placebo group, after consuming the experimental candy. [Test 2]-In order to measure visceral fat by means of CT scanning, 102 volunteers aged 26 to 69 years with body mass indices (BMI) between 25 and 30 participated in the study. The subjects were divided at random into two different groups as for Test 1 . The test period consisted of a 2 -wk pre-evaluation phase to screen the participants, a 20 -wk consumption period and a 4 -wk post-evaluation phase. A significant reduction in visceral fat only occurred in the $\beta$-conglycinin group. This study showed that $\beta$-conglycinin is an effective food ingredient that will be of use to reduce high serum TG concentrations and to prevent obesity.
\end{abstract}

J Atheroscler Thromb, 2006; 13:247-255.

Key words; Anti-obesity, Soybean $\beta$-conglycinin, Triacylglycerol, Visceral fat

\section{Introduction}

Hypercholesterolemia has been recognized to be a major risk factor for cardiovascular disease. However, recently, multiple risk factor clustering syndrome, or metabolic syndrome, has been noted as a highly atherogenic state independent of hypercholesterolemia.

In this syndrome, a variety of disorders, includ-

Address for correspondence: Mitsutaka Kohno, Food Science Research Institute, Fuji Oil Co., Ltd., Sumiyoshi, Izumisano, Osaka 598-8540, Japan.

E-mail: 860046@so.fujioil.co.jp

Received: April 17, 2006

Accepted for publication: July 20, 2006 ing hypertriglyceridemia cluster in one individual and visceral fat accumulation, is shown to act as a key player.

The US Food and Drug Administration (FDA) has approved for food labeling the health claim that the consumption of $25 \mathrm{~g}$ of soy protein isolate (SPI) per day reduces the risk of heart disease ${ }^{1)}$. This reduction of heart disease risk results from decreases in the serum cholesterol and triacylglycerol (TG) levels mediated by SPI ${ }^{2)}$. Many studies on the hypocholesterolemic effects of SPI support the hypothesis that polypeptides with high bile acid-binding capacity could inhibit the reabsorption of bile acid in the ileum, or decrease the micellar solubility of cholesterol in small 
intestinal epithelial cells and decrease the serum cholesterol level ${ }^{3-6)}$. SPI is mainly composed of two major storage proteins, glycinin and $\beta$-conglycinin. Previously, it was reported by this laboratory that $\beta$-conglycinin decreased plasma TG concentrations in young and adult rats $^{7)}$, and that $\beta$-conglycinin reduced TG levels in patients with hyperlipidemia who consumed $\beta$-conglycinin for 4 weeks in a small-scale clinical tri$\mathrm{al}^{8)}$. Moreover, $\beta$-conglycinin consumption was shown to reduce or suppress increases in the body fat ratio in healthy female volunteers with a high baseline body fat ratio by the bioelectrical impedance method $^{9,10)}$.

These reports suggested that $\beta$-conglycinin may be a food ingredient that could be used to prevent and/ or ameliorate lifestyle-related diseases, such as hyperlipidemia and obesity. A mechanism for the hypolipidemic activity of soybean $\beta$-conglycinin was reported. It was found that soybean $\beta$-conglycinin lowered the activity of fatty-acid synthase and increased the activities of $\beta$-oxidation enzymes, and that fecal excretion of TG was high in $\beta$-conglycinin-fed mice and rats ${ }^{11,12)}$.

This study was performed to evaluate the efficacy of soybean $\beta$-conglycinin in lowering the human serum TG level, as well as the reduction of visceral fat observed with computed tomography (CT) scan around the umbilicus ${ }^{13)}$, in a randomized controlled trial (RCT).

\section{Materials}

\section{Experimental Food}

Soybean $\beta$-conglycinin was manufactured by the method developed previously ${ }^{14)}$, and administered in the form of candy.

The $\beta$-conglycinin product consisting of $88 \%$ pure $\beta$-conglycinin, $5 \%$ soy protein, $2 \%$ minerals and $5 \%$ water was sterilized for food use and spray dried. The composition of the test candy is shown in Table $\mathbf{1}$. The test candy contained $0.625 \mathrm{~g}$ of $\beta$-congycinin product per piece. For the control experiment, placebo candy with the same taste as the test candy was produced by replacing $\beta$-conglycinin with the milk protein casein (Table $\mathbf{1}$ ).

\section{Subjects}

All of the test subjects were between 26 and 69 years of age.

Individuals undergoing treatment for hyperlipidemia, diabetes or liver dysfunction or with food or soybean allergies were excluded from the study. [Test 1] -According to the guidelines of the Japan Atherosclerosis Society ${ }^{15)}$, the upper limit of the normal range for serum TG is $150 \mathrm{mg} / \mathrm{dL}(1.69 \mathrm{mmol} / \mathrm{L})$, concen-
Table 1. Composition of test and placebo candy

\begin{tabular}{lcc}
\hline & Test $(\mathrm{g})$ & Placebo $(\mathrm{g})$ \\
\hline Powdered $\beta$-conglycinin & 0.63 & - \\
Commercial casein & - & 0.63 \\
Maltose & 0.55 & 0.55 \\
Sucrose & 0.19 & 0.19 \\
Powdered fruit juice & 0.05 & 0.05 \\
Flavoring & 0.03 & 0.03 \\
Citric acid & 0.06 & 0.06 \\
Sucrose fatty-acid ester & 0.07 & 0.07 \\
\hline Total/one piece of candy & 1.58 & 1.58 \\
\hline
\end{tabular}

trations above this range being regarded as hyperlipidemic.

Subjects were screened twice before enrolment in the trial, to ensure that they were slightly hyperlipidemic with serum TG concentrations higher than 1.69 $\mathrm{mmol} / \mathrm{L}$. Seven hundred and forty-four volunteers were asked to complete a meal questionnaire including the TG value and to provide a blood sample $2 \mathrm{wk}$ before the start of the study. Then, we designed a test period of a 2-wk pre-evaluation phase eating dinner of about $700 \mathrm{kcal}$ per day, which was supplied by the Institute of General Health Development Co. Ltd. (Tokyo, Japan) to screen subjects. The high serum TG levels in a considerable number of subject candidates fell to below $1.69 \mathrm{mmol} / \mathrm{L}$. The 138 subject candidates who still had high serum TG levels were registered as subjects and returned to regular daily meals. [Test 2]-According to the guidelines of the Japan Society for the Study of Obesity ${ }^{16)}$, a body mass index (BMI) between 25 and 30 is regarded as indicating obesity. Two hundred and fifteen volunteers were asked to complete a meal questionnaire about their dietary habits, 2 wk before the start of the study. One hundred and two subjects with slight hyperlipidemia with waist measurements of more than $85 \mathrm{~cm}$ (male) and $90 \mathrm{~cm}$ (female) showing BMI 25-30 were registered to participate in the study.

In compliance with the principles of the Helsinki Declaration and the study protocol, the purpose and methodology of the study, and the rights of the subjects were explained in advance and written consent was obtained from all volunteers.

\section{Methods}

\section{Test Design} design.

The study used a double-blind placebo-controlled 


\section{Test 1 for Serum TG}

The subjects were assigned at random to one of two groups: the test group only consumed the test candy containing soybean $\beta$-conglycinin $(n=69)$ and the placebo group only consumed the casein-containing placebo candy $(n=69)$. During the consumption period, blood samples were taken every $4 \mathrm{wk}$ and a meal questionnaire was completed for the $3 \mathrm{~d}$ preceding each blood test. Subjects were instructed to consume four pieces of candy twice a day containing a total of $5 \mathrm{~g}$ soybean $\beta$-conglycinin, i.e., before breakfast and dinner $(0.625 \mathrm{~g} \beta$-conglycinin per piece $\times$ four pieces $\times$ twice a day $=5 \mathrm{~g}$ ). Those in the placebo group were given the casein candy in the same manner.

\section{Test 2 for Visceral Fat}

The numbers of subjects of the test and placebo groups separated randomly were 50 and 52, respectively. The consumption period was $20 \mathrm{wk}$.

During the consumption period, blood samples were taken at $8,12,16$ and 20 wk. Meal questionnaires were completed throughout the test period. Subjects were instructed to consume four pieces of candy twice a day containing a total of $5 \mathrm{~g}$ soybean $\beta$-conglycinin per subject, i.e., before breakfast and dinnerthose in the placebo group were given the casein candy in a same manner.

The subjects were prohibited from drinking alcohol for $3 \mathrm{~d}$ before giving blood samples; however, they were free to drink alcohol and smoke moderately at all other times during the consumption period.

\section{Data Collection}

Blood samples were collected from each participant periodically from the start of the consumption period. Blood samples were collected at 09:00 in the morning and the subjects were required to fast from 20:00 the previous night. The following hematologi$\mathrm{cal}$ and serum biochemistry measurements were carried out by Scripps Reference Laboratory (Tokyo, Japan): white blood cell count, red blood cell count, hemoglobin, hematocrit, and platelet count; TG, free fatty acid, total cholesterol, high-density lipoprotein (HDL)-cholesterol, and low-density lipoprotein (LDL)-cholesterol for lipid metabolism; the enzymes glutamate-oxaloacetate transaminase (GOT), glutamate-pyruvate transaminase (GPT), gamma-glutamyl transpeptidase ( $\gamma$-GTP), alkaline phosphatase (ALP), and lactate dehydrogenase (LDH); total protein, albumin, blood urea nitrogen (BUN), uric acid, creatine, and total bilirubin for nitrogen metabolism; blood sugar and HbAlc for sugar metabolism; and the electrolytes $\mathrm{Na}, \mathrm{K}$, and $\mathrm{Cl}$. For Test 1, apolipoproteins
(Apo-A1, -2, -B, -C2, -3 and -E) and lipoprotein fractions were measured.

The concentrations of TG, total cholesterol and LDL-cholesterol were determined enzymatically. The HDL-cholesterol concentrations were measured by the synthetic polymer method. Apolipoprotein concentrations were measured by means of turbidimetric immunoassays. The concentrations of remnant-like particle (RLP)-cholesterol and RLP-TG of the lipoprotein fractions were measured by immunoseparation assays. The other lipoprotein fractions (Chylomicron, VLDL, LDL and HDL) were measured by the HPLC column method $^{17)}$ by Skylight-biotech (Tokyo, Japan).

At the time of blood collection, all subjects were also interviewed by a physician, in order to determine the occurrence of other subjective symptoms, and were assessed with a body composition meter, In body (Biospace Japan, Inc.), which calculated the body composition by bioelectrical impedance. For Test 2, the abdominal fat distribution was determined by five CT scans obtained around the umbilicus ${ }^{13)}$, such as the area at the umbilicus, two areas 1 and $2 \mathrm{~cm}$ above the umbilicus, and two areas 1 and $2 \mathrm{~cm}$ below the umbilicus.

During the study period, the subjects recorded their diet by weight for $3 \mathrm{~d}$ before each blood sample was collected for Test 1, and throughout the test period for Test 2. The amounts of nutrients ingested by each subject were calculated by a nutritionist using a computer program (Excel Eiyo-kun ver. 3.0; Kenpakusha, Ltd., Tokyo, Japan). The subjects were also instructed at the start of the trial to record any symptoms associated with the study in a questionnaire and to add a description, including the severity or time of occurrence, for the physician.

\section{Statistical Analysis}

The unpaired t-test was used for multiple group comparisons of the initial clinical data and calorie intake, and the blood test results and body-composition data collected during the trial period. Additionally, analysis of covariance (ANCOVA) was performed for changes in data, with the initial values as covariates, using Bonferroni's correction for multiple comparisons in order to reveal significant differences between two groups. SPSS (SPSS 10.0J for Windows; SPSS Co., Tokyo, Japan) was used for all statistical analyses and a 5\% significance level was applied in the twotailed tests. 
Table 2. Initial and final data of clinical characteristics and plasma levels of study subjects (Test 1)

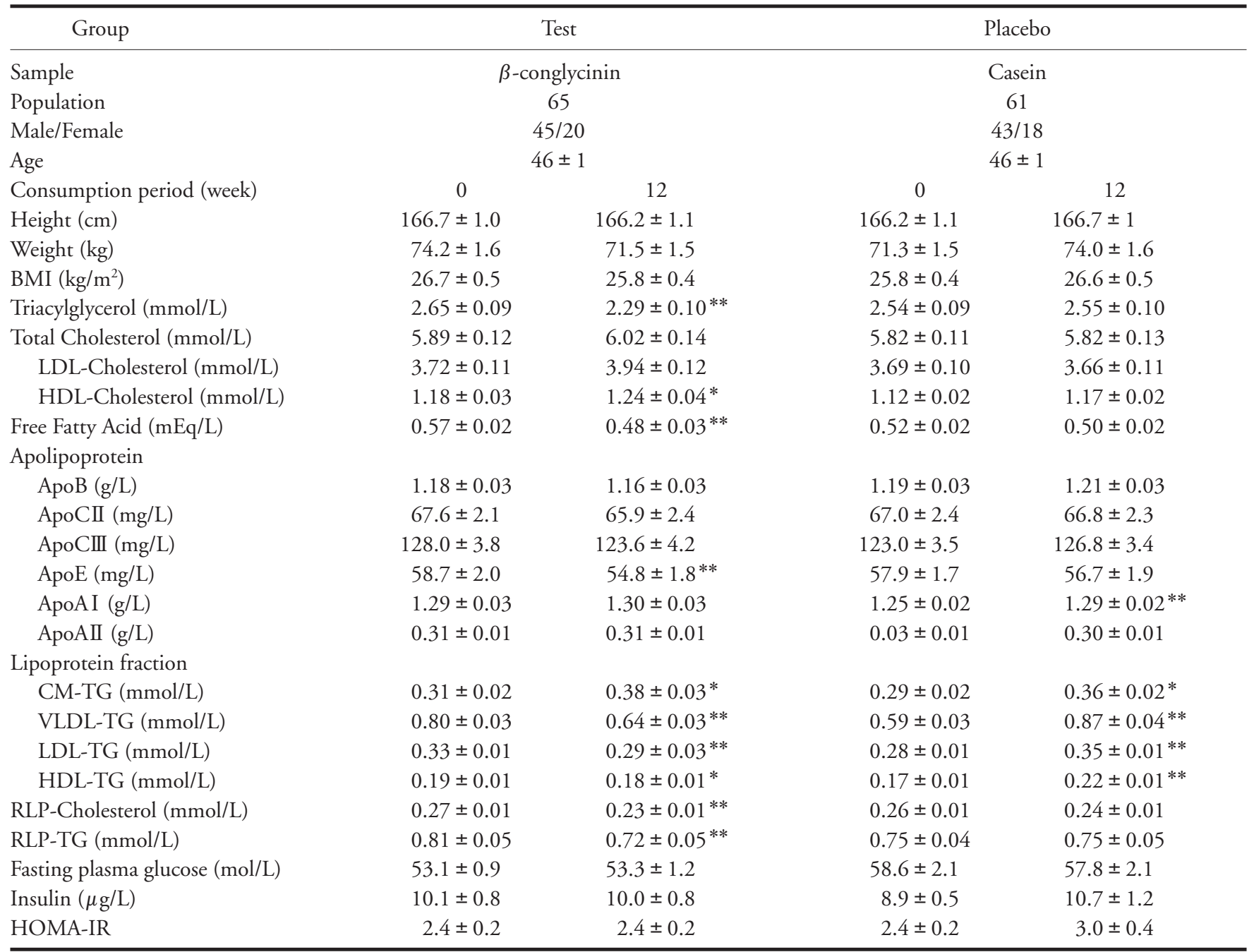

Data represent the means \pm SE.

$*$, ** show significant difference between initial and final data $\left({ }^{*} p<0.05 ; * * p<0.01\right)$.

\section{Results}

\section{Test 1 for Serum TG Subjects}

The background information on the 126 subjects in the both groups is summarized in Table 2. Data for 12 subjects were excluded, since they did not comply with the test conditions as described in the Methods section.

The TG values in the $\beta$-conglycinin and placebo groups were $2.65 \pm 0.09$ and $2.54 \pm 0.09 \mathrm{mmol} / \mathrm{L}$, respectively.

\section{Calorie Intake}

The diet data, which were obtained four times during the test period, are summarized in Table 3 .
Table 3. Calorie intake for three days before blood collection from study subjects (Test 1 )

\begin{tabular}{ccc}
\hline Group & Test & Placebo \\
\hline Calorie Intake & & \\
4 weeks (kcal/day) & $1937.4 \pm 53.6$ & $1941.6 \pm 47.5$ \\
8 weeks $(\mathrm{kcal} /$ day) & $1874.2 \pm 51.4$ & $1893.9 \pm 53.2$ \\
12 weeks $(\mathrm{kcal} /$ day) & $1874.2 \pm 46.0$ & $1946.4 \pm 56.8$ \\
post-evaluation (kcal/day) & $1883.0 \pm 62.3$ & $1863.5 \pm 59.3$ \\
\hline
\end{tabular}

Data represent the means $\pm \mathrm{SE}$.

There was no significant difference between the groups as to the total calorie intake or the consumption of individual nutrient groups (protein, lipid and carbohydrate) during the test period (data not shown). 


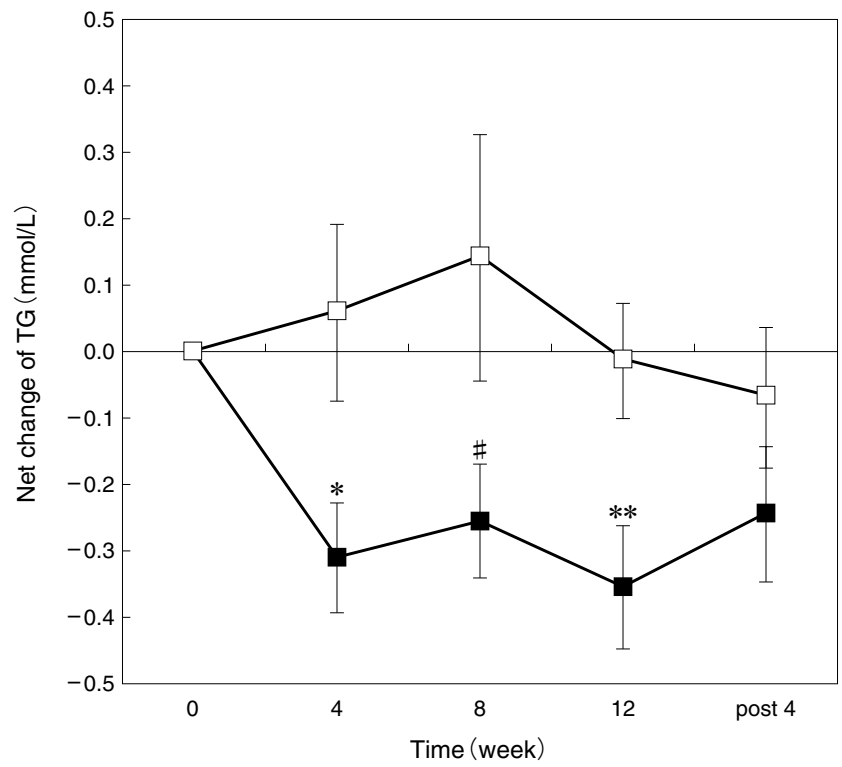

Fig. 1. Net changes in the mean serum TG concentration.

Test group (solid) and placebo group (open). Bars represent SEMs. ANCOVA $(P<0.05)$, using the initial TG concentration as a covariate, showed a significant difference $(* p<0.05$ and $* * p<0.01)$ and a significant tendency $\left({ }^{\#} p<0.1\right)$.

\section{Serum TG}

The mean serum TG concentration in the test group was initially $2.65 \pm 0.09 \mathrm{mmol} / \mathrm{L}$, and was significantly reduced after 4,8 and 12 wk of $\beta$-conglycinin consumption, i.e., by $0.31 \pm 0.08,0.26 \pm 0.09$ and $0.36 \pm 0.09 \mathrm{mmol} / \mathrm{L}$, respectively (Table 2 and Fig. 1). ANCOVA, using the initial serum TG concentration as a covariate, showed a significant difference after 4 and $12 \mathrm{wk}(4 \mathrm{wk}, \mathrm{F}=5.038, P=0.027$, and $12 \mathrm{wk}, \mathrm{F}=6.400, P=0.013)$, and a less significant reduction after $8 \mathrm{wk}(\mathrm{F}=3.335, P=0.070)$.

The mean serum free fatty acid concentration in the test group was initially $0.57 \pm 0.02 \mathrm{mEq} / \mathrm{L}$, and was significantly reduced to $0.48 \pm 0.03 \mathrm{mEq} / \mathrm{L}$ after 12 wk of $\beta$-conglycinin consumption (Table 2). The concentration in the placebo group did not change during the test period.

\section{Serum Apolipoprotein}

The mean apolipoprotein B (ApoB) concentration in the test group decreased from a baseline value of $1.18 \pm 0.03 \mathrm{~g} / \mathrm{L}$ by $0.024 \pm 0.016$ and $0.017 \pm 0.019$ g/L after 4 and 12 wk, respectively (Fig. 2). By contrast, the placebo group showed an increase from a baseline concentration of $1.19 \pm 0.03 \mathrm{~g} / \mathrm{L}$, i.e., by $0.020 \pm 0.017$ and $0.027 \pm 0.016 \mathrm{~g} / \mathrm{L}$, after 4 and 12

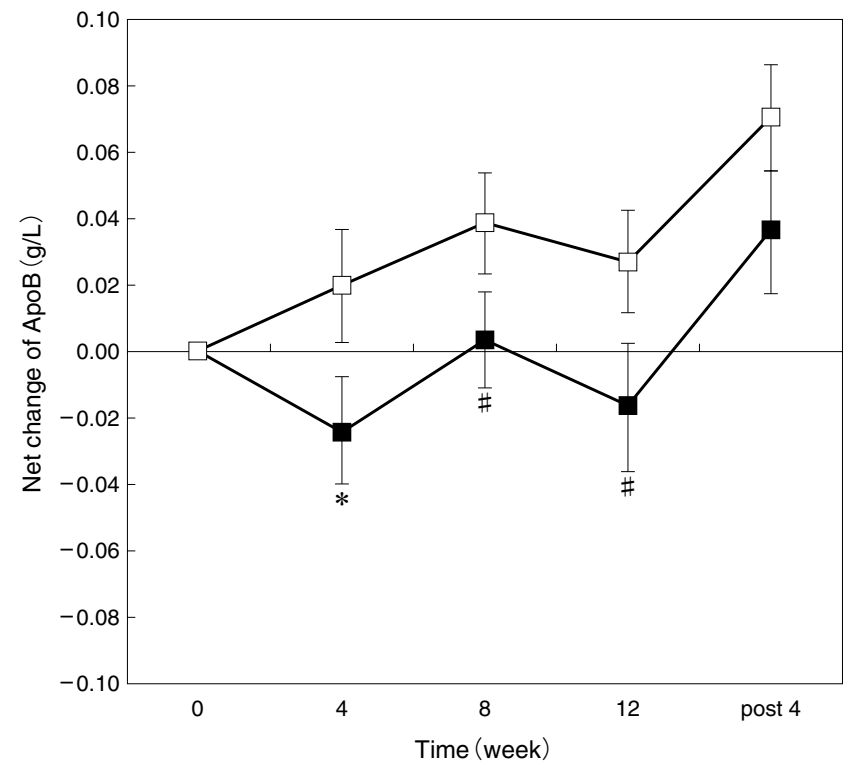

Fig. 2. Net changes in the mean apolipoprotein B (ApoB) concentration.

Test group (solid) and placebo group (open). Bars represent SEMs. An asterisk $(*)$ indicates a significant difference with ANCOVA, using the initial ApoB concentration as a covariate $(P<0.05)$. A pound sign $(\#)$ shows a reduction that did not reach the significance level of $P<0.1$.

wk. In particular, after 4 wk, the $A$ poB concentration in both groups significantly increased. ANCOVA, using the initial ApoB concentration as a covariate, showed a significant change between the two groups after 4 wk $(\mathrm{F}=3.994, P=0.048)$, and significant tendency after 8 and 12 wk $(8 \mathrm{wk}, \mathrm{F}=3.107, P=0.080$, and $12 \mathrm{wk}, \mathrm{F}=3.464, P=0.065)$.

The apolipoprotein CII concentration in the test group significantly decreased from the baseline value after 4 wk (data not shown), and apolipoprotein $\mathrm{E}$ in the same group significantly decreased after 4 and 12 wk (Table 2).

\section{Lipoprotein Fraction}

Chylomicron (CM)-TG, VLDL-TG, LDL-TG and HDL-TG were measured by HPLC ${ }^{17}$. The mean concentration of VLDL-TG in the test group significantly decreased from the baseline value after $12 \mathrm{wk}$ (Table 2). The placebo group showed a significant increase from the baseline. ANCOVA, using the initial concentration of VLDL-TG as a covariate, showed a significant change between the two groups $(\mathrm{F}=6.708$, $P=0.011)$. RLP-TG and cholesterol in the test group significantly decreased from the baseline value to 12 wk, respectively (Table 2). The placebo group showed no significant change from the baseline. ANCOVA, 
Table 4a. Initial and final data of clinical characteristics and plasma levels of study subjects (Test 2)

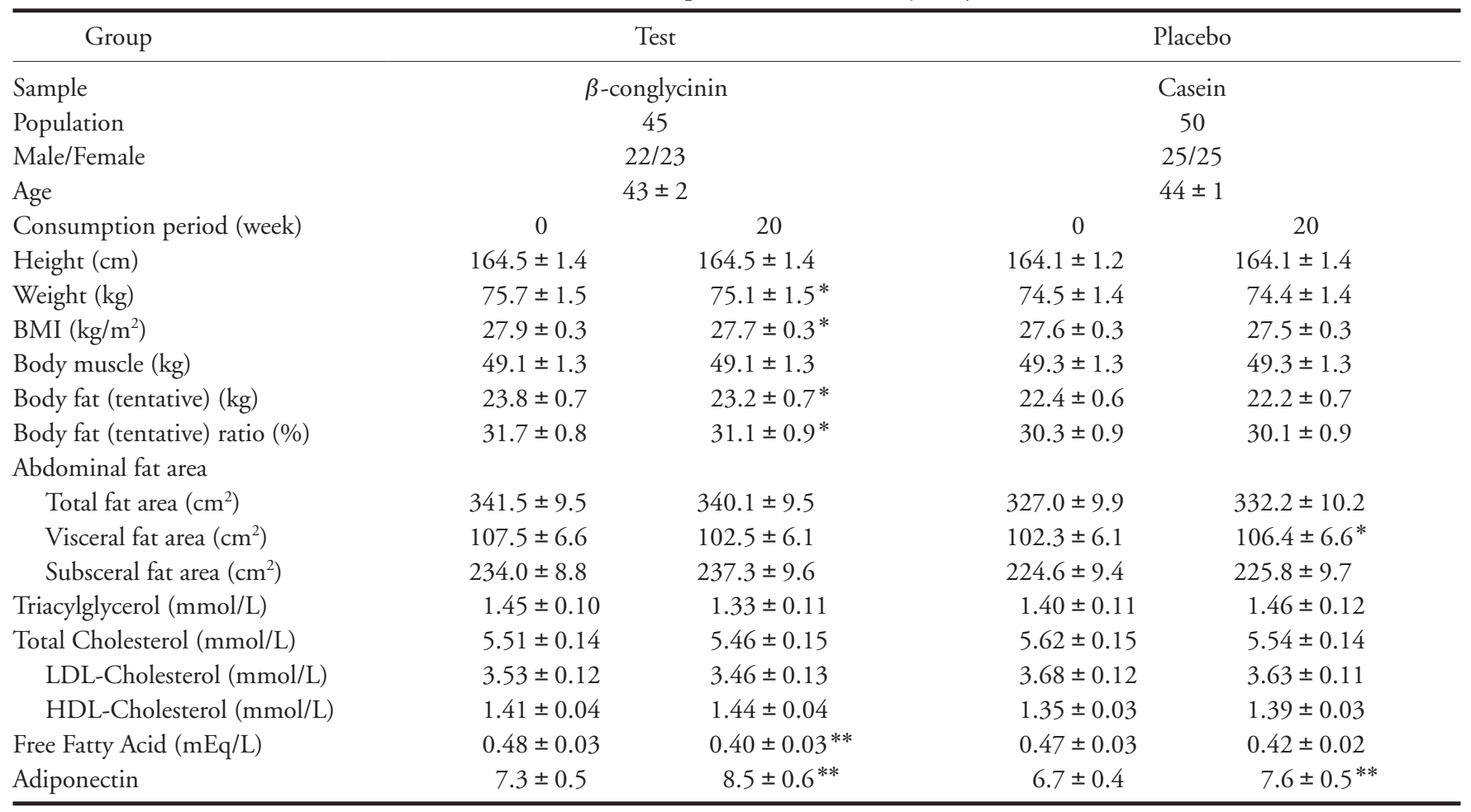

Data represent the means \pm SE.

$*$, ** show significant differences between initial and fainal data $\left({ }^{*} p<0.05 ;{ }^{* *} p<0.01\right)$.

Table $\mathbf{4 b}$. Initial and final data of clinical characteristics of obese subjects (Test 2)

\begin{tabular}{|c|c|c|c|c|}
\hline Group & \multicolumn{2}{|c|}{ Test } & \multicolumn{2}{|c|}{ Placebo } \\
\hline Population & \multicolumn{2}{|c|}{24} & \multicolumn{2}{|c|}{22} \\
\hline Consumption period (week) & 0 & 20 & 0 & 20 \\
\hline \multicolumn{5}{|l|}{ Abdominal fat area } \\
\hline Subsceral fat area $\left(\mathrm{cm}^{2}\right)$ & $217.5 \pm 11.9$ & $218.4 \pm 12.6$ & $216.4 \pm 14.1$ & $214.1 \pm 13.9$ \\
\hline
\end{tabular}

Data represent the means \pm SE.

* shows a significant difference between initial and final data $(p<0.05)$.

\# shows a significant different tendency between initial and final data $(p<0.1)$.

using the initial RLP-TG and cholesterol as covariates, showed significant reductions during the $\beta$-conglycinin consumption period (data not shown).

\section{Other Blood Tests}

Apart from the serum TG and apolipoprotein concentrations and the lipoprotein fraction, significant changes were not observed in blood hematology or biochemistry, such as the white blood cell count, red blood cell count, hemoglobin, hematocrit, platelet count, GOT, GTP, $y$-GTP, ALP, LDH, total protein, albumin or blood sugar level (data not shown).

\section{Test 2 for Visceral Fat}

Subjects

The background information on the subjects in both groups is summarized in Table 4a. Data for 7 subjects were excluded, since they did not comply with the test conditions as described in the Methods section. The visceral fat areas in the $\beta$-conglycinin and 
Table 5. Calorie intake and nutrient content of average daily diets during the test period before blood collection from study subjects (Test 2)

\begin{tabular}{ccc}
\hline Group & Test & Placebo \\
\hline Calorie Intake & & \\
4 weeks $(\mathrm{kcal} /$ day $)$ & $1943.7 \pm 65.3$ & $1963.9 \pm 69.8$ \\
8 weeks $(\mathrm{kcal} /$ day $)$ & $1924.8 \pm 61.6$ & $1815.1 \pm 60.2$ \\
12 weeks $(\mathrm{kcal} /$ day $)$ & $1907.1 \pm 63.3$ & $1829.9 \pm 62.0$ \\
16 weeks $(\mathrm{kcal} /$ day) & $1892.7 \pm 67.1$ & $1821.8 \pm 65.3$ \\
20 weeks $(\mathrm{kcal} /$ day) & $1885.6 \pm 69.2$ & $1841.7 \pm 70.3$ \\
post evaluation (kcal/day) & $1873.8 \pm 70.8$ & $1862.6 \pm 70.3$ \\
\hline
\end{tabular}

Data represent the means \pm SE.

placebo groups were $107.5 \pm 6.6$ and $102.3 \pm 6.1 \mathrm{~cm}^{2}$, respectively.

\section{Calorie Intake}

The diet data, which were obtained during the test period, are summarized in Table 5. Significant differences were not observed between the groups as to the total calorie intake or the consumption of individual nutrient groups (protein, lipid and carbohydrate) during the test period (data not shown).

\section{Abdominal Fat}

For abdominal fat distribution, an average of 5 CT areas was measured around the umbilicus. The mean visceral fat area in the test group was initially $107.5 \pm 6.6 \mathrm{~cm}^{2}$, and was reduced after $12 \mathrm{wk}$ of $\beta$ conglycinin consumption, and significantly reduced after 12 and 20 wk consumption and 4 wk post-evaluation, i.e., by $5.3 \pm 2.3 \mathrm{~cm}^{2}, 5.0 \pm 2.3 \mathrm{~cm}^{2}$ and $5.5 \pm$ $2.2 \mathrm{~cm}^{2}$, respectively (Table $\mathbf{4 a}$ and Fig. 3 ). By contrast, the placebo group showed a significant increase from the baseline of $102.3 \pm 6.1 \mathrm{~cm}^{2}$, i.e., by $4.2 \pm 1.6$ $\mathrm{cm}^{2}$ after $20 \mathrm{wk}$. ANCOVA, using the initial visceral area as a covariate, showed significant decreases caused by the intake of $\beta$-conglycinin after $20 \mathrm{wk}(\mathrm{F}=8.164$, $P=0.005)$, and the $4 \mathrm{wk}$ post-evaluation phase $(\mathrm{F}=$ 4.719, $P=0.032$ ).

Among the subjects, 46 (24 in the test group including 12 men and 12 women, and 22 in the placebo group including 13 men and 9 women) had larger visceral fat areas than $100 \mathrm{~cm}^{2}$ (Table $\mathbf{4 b}$ ). The mean visceral fat area of those subjects in the test group was initially $136.9 \pm 7.5 \mathrm{~cm}^{2}$, and was reduced after 12 and $20 \mathrm{wk}$ of $\beta$-conglycinin consumption, i.e., by 7.1 $\pm 4.0 \mathrm{~cm}^{2}$ and $6.6 \pm 3.8 \mathrm{~cm}^{2}$, respectively (Table $\mathbf{4 b}$ and Fig. 4).

They also showed a significant decrease, i.e., by $8.8 \pm 3.5 \mathrm{~cm}^{2}$ after the $4 \mathrm{wk}$ post-evaluation phase.

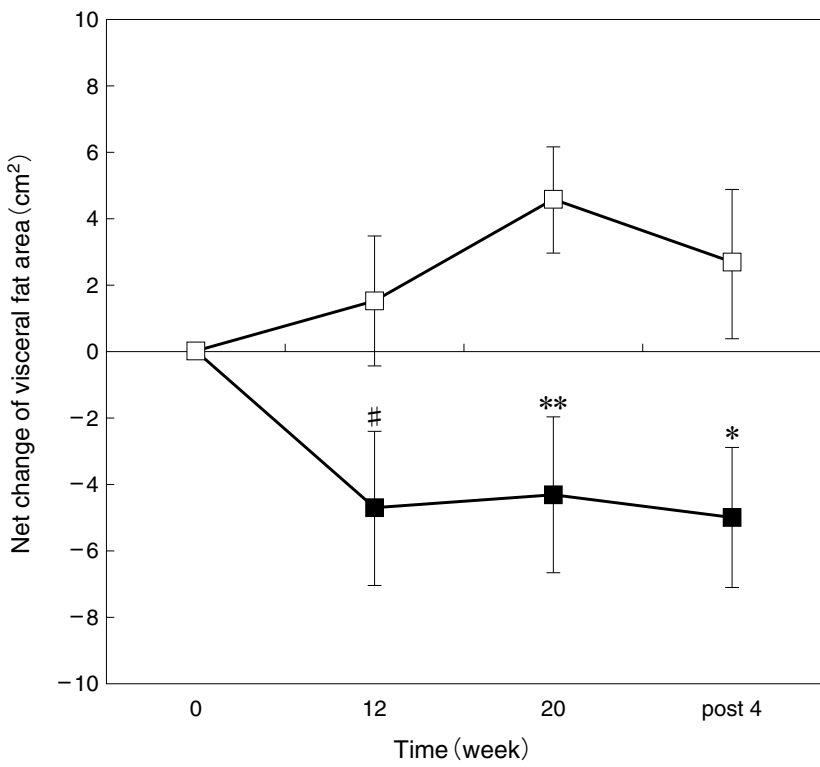

Fig. 3. Net changes in the mean visceral fat area.

Test group (solid) and placebo group (open). Bars represent SEMs. ANCOVA, using the initial visceral fat area as a covariate, showed significant differences between the two groups $\left({ }^{*} p<0.05\right.$ and $* * p<0.01)$ and a significant tendency $\left({ }^{*} p<0.1\right)$.

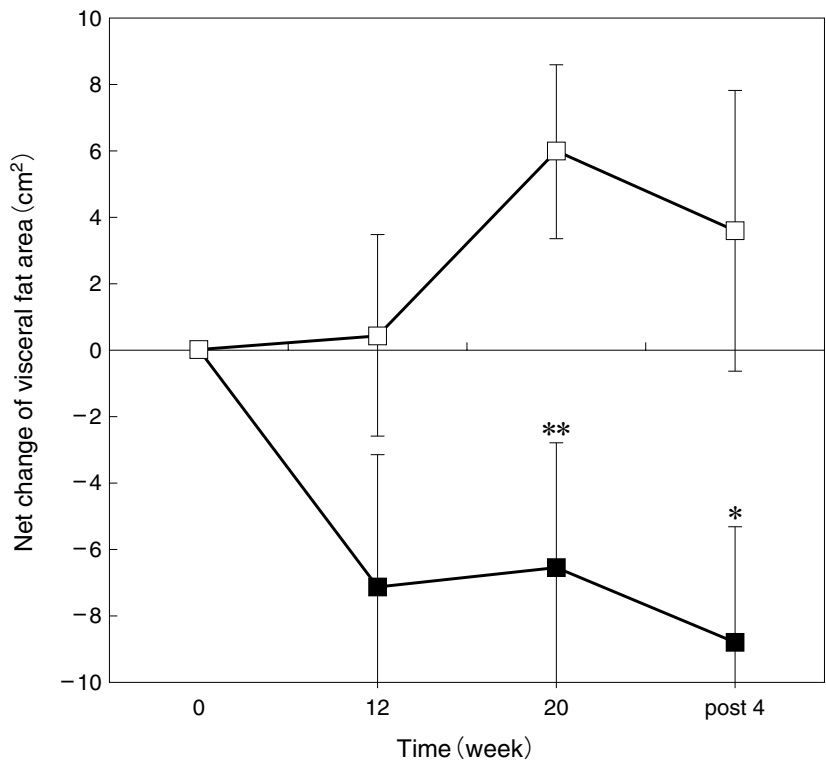

Fig.4. Net changes in the mean visceral fat area in the subjects with visceral fat areas greater than $100 \mathrm{~cm}^{2}$.

Test group (solid) and placebo group (open). Bars represent SEMs. ANCOVA, using the initial visceral fat area as a covariate, showed significant differences between the two groups $\left({ }^{*} p<0.05\right.$ and $* * p<0.01)$.

The placebo group of those subjects showed a significant increase from the baseline of $138.2 \pm 6.3 \mathrm{~cm}^{2}$, i.e., 
by $6.0 \pm 2.6 \mathrm{~cm}^{2}$, after $20 \mathrm{wk}$ (Table $\mathbf{4 b}$ and Fig. 4 ). The result of ANCOVA, using the initial visceral area as a covariate, showed a significant decrease caused by dietary $\beta$-conglycinin after 20 wk $(\mathrm{F}=7.634, P=$ $0.008)$ and the 4 wk post-evaluation phase $(\mathrm{F}=5.206$, $P=0.028$ ).

\section{Serum Lipids}

The mean serum TG in the test group was reduced after 20 wk of $\beta$-conglycinin consumption, but this reduction was not significant (Table 4a). The mean serum free fatty acid concentration in the test group was initially $0.48 \pm 0.03 \mathrm{mEq} / \mathrm{L}$, and was significantly reduced to $0.40 \pm 0.03 \mathrm{mEq} / \mathrm{L}$ after $20 \mathrm{wk}$ of $\beta$-conglycinin consumption (Table 4a). The concentration in the placebo group did not change during the test period.

\section{Discussion}

Prior to Test 1 for serum TG, subjects with high serum TG levels were screened by their intake of restricted dietary calories for two weeks. The high serum TG levels in a considerable number of subject candidates were lowered to below $1.69 \mathrm{mmol} / \mathrm{L}$. The candidate subjects, who still had high serum TG levels, participated in the test as subjects and returned to have regular daily meals. The subjects in Test 2 for visceral fat were screened by the similar methods as for Test 1 . The increases in serum TG and visceral fat with the placebo may have been caused by such a change to daily meals. The three-month and five-month regulation for the test appeared to be hard for the subject volunteers, although most of them complied with the conditions and thus contributed to this study. Finally, it was shown that serum TG and visceral fat were lowered by dietary $\beta$-conglycinin.

Soy has been cultivated and utilized as a food since ancient times. The US Food and Drug Administration (FDA) has approved for food labeling the health claim that the consumption of $25 \mathrm{~g}$ soy protein isolate per day, including $5 \mathrm{~g} \beta$-conglycinin ${ }^{18)}$, reduces the risk of heart diseases ${ }^{1)}$ Hence, subjects who eat $5 \mathrm{~g}$ $\beta$-conglycinin a day appear safe.

Daily consumption of $5 \mathrm{~g} \beta$-conglycinin per subject significantly lowered the serum TG concentration. Simultaneously, the apo B and VLDL-TG concentrations were significantly decreased.

Hence, $\beta$-conglycinin consumption may specifically affect TG metabolism. In addition, the intake of $5 \mathrm{~g} \beta$-conglycinin per day decreased visceral fat. It seems difficult to determine the precise CT area of visceral fat. In order to overcome this problem, we devel- oped a means of measuring CT areas more precisely. Five CT areas around the umbilicus were measured and averaged per subject. As a result, statistically significant data were obtained. Dietary $\beta$-conglycinin was shown to decrease visceral fat. Visceral fat is now recognized as the key factor related to metabolic syndrome $^{19,20)}$. During the test period, adiponectin significantly increased (Table 4a), but there was no change between test and placebo groups. However, it cannot be excluded that the decrease in visceral fat may contribute to a decrease in portal free fatty acids. Indeed, serum free fatty acids in the test group significantly decreased (Table 4a).

The details of the mechanism underlying the decreased TG synthesis and accumulation caused by $\beta$ conglycinin remain unknown. However, it has been reported in mice and rats ${ }^{11,12)}$ that feeding $\beta$-conglycinin lowered fatty-acid synthetic activity, and increased the activities of $\beta$-oxidation enzymes such as carnitine palmitoyl transferase and acyl-coA oxidase in the liver, and that fecal excretion of TG was increased.

This suggests that the concentration of the substrate (free fatty acids) for TG synthesis was decreased by $\beta$-conglycinin consumption. Biochemical and molecular biological studies are currently under way.

The effectiveness of the daily intake of $5 \mathrm{~g} \beta$ conglycinin, as described above, may support the FDA recommendation for the consumption of $25 \mathrm{~g}$ SPI a day, in which $5 \mathrm{~g} \beta$-conglycinin is included ${ }^{18)}$. Therefore, $\beta$-conglycinin might be an important food component for the prevention and/or amelioration of visceral fat syndrome, so-called metabolic syndrome.

\section{Acknowledgment}

We thank the Institute of General Health Development Co., Ltd. (Tokyo, Japan) for supporting this study.

\section{References}

1) Food and Drug Administration. Food labeling health claims; soy protein and coronary heart disease. Fed Regist, 1999; 64:57699-57733

2) Anderson JW, Johnstone BM, and Cook-Newell ME: Meta-analysis of the effects of soy protein intake on serum lipids. N Engl J Med, 1995; 333:276-282

3) Nagaoka S, Miwa K, Eto M, Kuzuya Y, Hori G, and Yamamoto K: Soy protein peptic hydrolysate with bound phospholipids decreases micellar solubility and cholesterol absorption in rats and caco-2 cells. J Nutr, 1999; 129:17251730

4) Iwami K, Sakakibara K, and Ibuki F; Involvement of post-digestion 'hydrophobic' peptides in plasma choles- 
terol-lowering effect of dietary plant proteins. Agric Biol Chem, 1986; 50:1217-1222

5) Sugano M, Yamada Y, Yoshida K, Hashimoto Y, Matsuo T, and Kimoto M: The hypocholesteroletic action of the undigested fraction of soybean protein in rats. Atherosclerosis, $1988 ; 72: 115-122$

6) Sugano M, Goto S, Yamada Y, Yoshida K, Hashimoto Y, Matsuo T, and Kimoto M: Cholesterol-lowering activity of various undigested fractions of soybean protein in rats. J Nutr, 1990; 120:977-985

7) Aoyama T, Kohno M, Saito T, Fukui K, Takamatsu K, Yamamoto T, Hashimoto Y, Kirotsuka M, and Kito M: Reduction by phytate-reduced soybean $\beta$-conglycinin of plasma triglyceride level of young and adult rats. Biosci Biotechnol Biochem, 2001; 65:1071-1075

8) Kambara H, Hirotsuka M, Takamatsu K, and Kito M; A lowering effect of soybean $\beta$-conglycinin on serum triglyceride level in humans. Ther Res, 2002; 23:85-89

9) Kambara H, Baba T, Miyazaki C, Hirotsuka M, and Kito $\mathrm{M}$; A lowering effect of soybean $\beta$-conglycinin on body fat ratio in human. Ther Res, 2003; 24:861-866

10) Baba T, Ueda A, Kohno M, Fukui K, Miyazaki C, Hirotsuka $M$, and Ishinaga $M$ : Effects of soybean $\beta$-conglycinin on body fat ratio and serum lipid levels in healthy volunteers of female university students. J Nutr Sci Vitaminol (Tokyo), 2004; 50:26-31

11) Moriyama T, Kishimoto K, Nagai K, Urade R, Ogawa T, Utsumi S, Maruyama N, and Maebuchi M: Soybean $\beta$ conglycinin diet suppresses serum triglyceride levels in normal and genetically obese mice by induction of $\beta$-oxidation, downregulation of fatty acid synthase, and inhibition of triglyceride absorption. Biosci Biotechnol Biochem, 2004; 68:352-359

12) Fukui K, Kojima M, Tachibana N, Kohno M, Takamatsu
K, Hirotsuka M, and Kito M: Effects of soybean $\beta$-conglycinin on hepatic lipid metabolism and fecal lipid excretion in normal adults rats. Biosci Biotechnol Biochem, 2004; 68:1153-1155

13) Yoshizumi $T$, Nakamura $T$, Yamane M, Islam $A H$, Menju M, Yamasaki K, Arai T, Kotani K, Funahashi T, Yamashita S, and Matsuzawa Y: Abdominal fat: standardized technique for measurement at CT. Radiology, 1999; 211:283286

14) Saito T, Kohno M, Tsumura K, Kugimiya W, and Kito M: Novel method using phytase for separating soybean $\beta$ conglycinin and glycinin. Biosci Biotechnol Biochem, 2001; 65:884-887

15) Japan Atherosclerosis Society (JAS) Guidelines for Diagnosis and Treatment of Atherosclerotic Cardiovascular Diseases. pp5-7, 2002 (in Japanese)

16) Examination Committee of Criteria for 'Obesity Diseases' in Japan; Japan Society for the Study of Obesity. New criteria for 'obesity diseases' in Japan. Circ J, 2002;987-992

17) Usui S, Hara Y, Hosaki S, and Okazaki M: A new on-line dual enzymatic method for simultaneous quantification of cholesterol and triglycerides in lipoproteins by HPLC. J Lipid Res, 2002; 43:805-814

18) Samoto M, Maebuchi M, Miyazaki C, Kugitani H, Kohno $M$, Hirotsuka M, and Kito M; Abundant proteins associated with lecithin in soy protein isolate. Food Chem, 2006 (in press)

19) Matsuzawa Y: Pathophysiology and molecular mechanisms of visceral fat syndrome: the Japanese experience. Diabetas Metab Rev, 1997; 13:3-13

20) Matsuzawa Y: Therapy insight: adipocytokines in metabolic syndrome and related cardiovascular disease. Nat Clin Pract Cardiovasc Med, 2006; 3:35-42 